\title{
Watching cement dry: a necessary but costly irritation in lower limb orthopaedics
}

\author{
What is the cost to the NHS of staff waiting for cement to dry?
}

\section{A B Scrimshire core surgical trainee year 1, E M Holt consultant orthopaedic surgeon}

University Hospital South Manchester, North West Deanery, Manchester

Polymethyl-methacrylate (PMMA), synthesised in 1902, has many uses, including in aircraft windows and dentures. But it was not until 1959 that PMMA cement (bone cement) was used in hip replacements, to secure femoral and acetabular implants, by a UK pioneer of the hip replacement operation, John Charnley. Antibiotics were added to the cement to reduce infection rates, and today over a million implants have been fixed with bone cement worldwide. ${ }^{1}$

Bone cement typically comes in two parts: a dry powder and a liquid component. ${ }^{2}$ The cementing process has four stages: mixing of the two components, by hand in a sterile bowl or in a sealed vacuum container, to remove fumes and small air bubbles and reduce the cement's porosity; the "pick-up" stage, when the consistency of the cement changes enough for it to become workable; the working stage, during which it retains a workable consistency and is applied to bone or implants and the implants inserted; and the setting stage, when the cement hardens (dries). ${ }^{3}$ After implant insertion there may be some activity, but generally the operating team is simply waiting and watching the cement dry before proceeding.

Cement type, warmer temperature (of the theatre, patient, and cement), lower humidity, and vacuum mixing can reduce the time taken for cement to dry. ${ }^{45}$

We aimed to uncover the financial cost to the NHS in England and Wales of watching bone cement dry.

\section{Methods}

The optimum operating theatre temperature for working with bone cement is said to be $18.3^{\circ} \mathrm{C},{ }^{6}$ with standard humidity around $55 \% .^{7}$ Data on cement characteristics at $18.3^{\circ} \mathrm{C}$ for 15 different bone cements, hand mixed at standard humidity, have been analysed. ${ }^{3-13}$

We collected data on the number of cemented lower limb orthopaedic procedures performed in NHS hospitals in 2012 from the National Joint Registry and the National Hip Fracture Database. ${ }^{14}{ }^{15}$ Data on staff pay came from the British Medical
Association and NHS Careers. ${ }^{16-18}$ With these data we estimated the total cost of watching cement dry.

\section{Results}

The mean time from the start to the end of the cementing process for the 15 cements analysed was 13 minutes. Typically implants are inserted no later than six minutes into the cementing process. ${ }^{190}$ Therefore an average of seven minutes in each procedure was spent watching cement dry.

From 1 April 2011 to 31 March 2012 a total of 18530 elective primary cemented hip replacements, 9185 hybrid hip replacements, 3480 cemented hip revisions (2139 femoral prostheses and 1341 acetabular), 47797 cemented primary knee replacements, 247 hybrid knee replacements, and 15 cemented primary ankle replacements took place in NHS hospitals. ${ }^{14} 21$ Hybrid procedures are those that use a combination of cemented and uncemented implants. ${ }^{22}{ }^{23}$ From 1 January 2011 to 31 December 2011 a total of 20920 cemented hip hemiarthroplasties took place for fractured neck of femur. ${ }^{15}$ These figures give an annual total of 100174 lower limb orthopaedic procedures using bone cement in NHS hospitals. Given a time spent watching cement dry of seven minutes in each procedure, a total of $7 \times 100174$ procedures=701 218 minutes (11 687 hours or 487 days or 1.33 years) is spent watching cement dry in the NHS each year.

An operating team for joint replacement consists of a consultant anaesthetist, an anaesthetic assistant, a consultant orthopaedic surgeon, an orthopaedic registrar, a scrub nurse, and an operating department practitioner. The annual salary for a first year consultant anaesthetist is $£ 75249$ ( $€ 90474$; \$123 062), for a band 6 anaesthetic assistant $£ 25783$, a first year orthopaedic consultant $£ 75249$, a first year orthopaedic registrar $£ 32852$, a band 6 scrub nurse $£ 25783$, and a band 5 operating department practitioner $£ 21388 .{ }^{16-18}$ These figures give a total cost of $£ 256$ 304 a year. 
These pay scales are for a standard 40 hour working week, not including banding. To adjust for continuous operating the cost must be adjusted by a factor of 4.2 (168 hours a week $\div 40)$. Therefore each year the NHS spends a total of $£ 1.43 \mathrm{~m}$ $(1.33 \times £ 256304 \times 4.2)$ having specialists watch cement dry in lower limb orthopaedic surgery.

\section{Discussion}

The National Joint Registry annual report for 2012 noted a decline in the use of cemented prostheses, with an increasing number of surgeons preferring non-cemented implants. However, as our study shows, cementing is still common practice, and the drying process is proving costly.

In our calculation we used the most junior pay bands and therefore the cheapest. We assumed that cement was prepared and used only once in each procedure, which may not always be the case. These assumptions mean our final figure may be an underestimate. But we also assumed that cements were hand mixed and that after insertion of the implant the entire operating team was simply waiting for the cement to dry, which may not always be the case. The anaesthetist may be listening to the beeping of his or her machines for a transient drop in blood pressure or oxygen saturations after cement insertion, as occurs in around $19 \%$ of patients. ${ }^{24}$ The surgeon and scrub team may use this time to reflect, teach, clear their work surfaces, and plan their next steps. Our assumption that theatre staff take on a state of statuesque inactivity after implant insertion therefore counters the previous assumptions, improving the reliability of our calculation of the cost of watching cement dry.

Given the current drive for cost savings in the NHS, it may seem ridiculous that we spend more than $£ 1.4 \mathrm{~m}$ a year watching cement dry. However, while perhaps irritating, it is a necessary step, as improper surgical handling of bone cement is a major cause of prosthetic loosening. ${ }^{25}$

Perhaps more use of cheaper implants, uncemented implants, and new technologies, such as faster setting cement, ${ }^{26}$ will reduce this cost. However, it is likely that such developments would give rise to complications of their own. ${ }^{27}$

Conflicts of interest: None declared.
Provenance and peer review: Not commissioned; peer reviewed.

1 Biomet. Bone cement: history. www.bonecement.com/cementing-techniques/bonecement/ history.

2 Dee R. Principles of orthopaedic practice. 2nd ed. McGraw-Hill Medical, 1997.

3 Stryker. OR handbook for Simplex P bone cement. http://isulmed.com/archivos/ complementos-cemento/Cemento\%20Simplex\%20p\%20-\%20Handbook\%20(ingles).pdf. Biomet. Bone cement: polymerization. www.bonecement.com/cementing-techniques/ bonecement/polymerization.

5 Poitout D G. Biomechanics and biomaterials in orthopaedics. Springer, 2004.

6 Rixford E. The optimum temperature of operating rooms. Cal West Med 1924;22:599-601.

7 Mackenzie A. Hazards in the operating theatre: environmental control. Ann R Coll Surg Engl 1973;52:361-5.

8 Heraeus Medical. Palacos LV\&G bone cement: instructions for use [product leaflet].

9 Heraeus Medical. Palacos LV bone cement: instructions for use [product leaflet].

10 Heraeus Medical. Palacos MV\&G Bone cement: instructions for use [product leaflet].

11 Heraeus Medical. Palacos R Bone cement: instructions for use [product leaflet].

12 Heraeus Medical. Palacos R\&G Bone cement: instructions for use [product leaflet].

13 DePuy. Bone cement comparison chart. www.depuy.com/sites/default/files/products/files/ DO_Bone_Cement_Setting_Time_Chart.pdf.

14 National Joint Registry. 9th annual report: 2012. www.njrcentre.org.uk/NjrCentre/Portals/ 0/Documents/England/Reports/9th_annual_report/NJR\%209th\%20Annual\%20Report\% 202012.pdf.

15 National Hip Fracture Database. National report 2012. www.nhfd.co.uk/003/hipfractureR. nsf/0/da44e3a946a14e4180257a6f001eb4db/\$FILE/NHFD\%20National\%20Report\% 202012.pdf.

16 British Medical Association. Consultants salary scales and awards from April 2013. http: //bma.org.uk/practical-support-at-work/pay-fees-allowances/pay-scales-consultants.

17 NHS Careers. Agenda for change: pay rates (from 1 April 2013). www.nhscareers.nhs. uk/working-in-the-nhs/pay-and-benefits/agenda-for-change-pay-rates/.

18 British Medical Association. 2013 pay scales for doctors in training (from April). http://bma. org.uk/practical-support-at-work/pay-fees-allowances/pay-scales-juniors.

19 Wheeless CR. Wheeless' textbook of orthopaedics: cementing technique for THR. www. wheelessonline.com/ortho/cementing_technique_for_thr.

20 Darmanis SN, Hubble MJ, Howell JR, Whitehouse SL, Timperley AJ. Benefits of using modern cementing techniques in the acetabulum: the rim cutter. J Orthop Surg 2012;20:316-21.

21 National Joint Registry. 9th annual report 2012: Prosthesis used in hip, knee and ankle replacement procedures 2011. www.njrcentre.org.uk/njrcentre/Portals/O/Documents/ England/Reports/9th_annual_report/Prostheses\%20used\%20in\%20hip\%20knee\%20and\% 20ankle\%20replacements\%202011.pdf.

22 American Academy of Orthopaedic Surgeons. Cemented and cementless knee replacement. http://orthoinfo.aaos.org/topic.cfm?topic=A00360.

23 American Academy of Orthopaedic Surgeons. Hip replacements. http://orthoinfo.aaos. org/topic.cfm?topic=A00355.

24 Donaldson AJ, Thomson HE, Harper NJ, Kenny NW. Bone cement implantation syndrome. Br J Anaesth 2009;102:12-22.

25 Canale ST. Campbell's operative orthopaedics. 9th ed, vol 1. Mosby, 1998.

26 DePuy. CMW2 bone cement [product information]. www.depuy.com/healthcareprofessionals/product-details/depuy-cmw2-bone-cement-20g.

27 Donnelly L. NHS Hospitals to be banned from fitting metal-on-metal hip replacements after high failure rate. Telegraph 25 Oct 2013. www.telegraph.co.uk/health/nhs/10406198/ NHS-hospitals-to-be-banned-from-fitting-metal-on-metal-hip-replacements-after-highfailure-rate.html.

Accepted: 10 November 2013

Cite this as: BMJ 2013;347:f7395

(c) BMJ Publishing Group Ltd 2013 